\title{
Children's Views and Practices Regarding Online Advertising
}

\author{
An Interview Study with Swedish Nine-Year-Olds
}

\author{
Carolina Martínez, Gunilla Jarlbro \& Helena Sandberg
}

\begin{abstract}
This article focuses on children's relationship with online advertising, a topic which is insufficiently researched. Individual interviews $(n=20)$ were conducted with Swedish children to gain insight into their views and practices regarding advertising on the internet. The interview results are interpreted in relation to de Certeau's (1984) theory of practices in everyday life, and New dimensions regarding the concept of tactics are highlighted in the conclusion. The results suggest that children have an ambivalent or negative view of online advertising. They report on avoidance tactics used in order to escape advertisements, but they also sometimes find it difficult to cope with advertisements due to their frequent appearance, color and motion. The children also report on their uses of online advertising as entertainment, and the authors stress the need for policymakers to consider whether the regulatory framework for broadcasting could be extended to cover online advertising.
\end{abstract}

Keywords: children, tweens, online advertising, internet, de Certeau, commercialization

\section{Introduction}

Internet usage is an integral part of many Swedish children's everyday lives. In 2012, $48 \%$ of Swedish nine-year-olds used the internet on a daily basis (Findahl 2012a: 19). Common activities that children engage in, such as playing online games and watching video clips (Ungar \& Medier 2010: 47), take place in a commercial media environment. Advertising is present on some of the most popular websites used by children, for instance YouTube and Spela.se, a Swedish online gaming site (Småungar \& Medier 2010: 21). In Sweden, 6.5 billion crowns were invested in advertising on the internet in 2011, and the internet is also where investments are increasing the most, following mobile advertising ('Marknadskommunikation 2011', IRM). This is accompanied by a growing interest in the tween segment (approx. 8-12-year-olds) amongst marketers (Buckingham and Tingstad 2010: 1; Tufte 2007: 93).

Despite these trends, which all together can be said to contribute to the ongoing commercialization of childhood (Wasko 2010: 113), there is still little research on how children relate to advertising on the internet. Most research is focused on children and television advertising (Buijzen, Van Reijmersdal and Owen 2010: 428; Ekström and 
Sandberg 2010: 52). Research on internet advertising is chiefly content analysis with particular attention to unhealthy food (see for instance Sandberg 2011). Research with a focus on the child audience (below the age of twelve) deals with children's abilities to recognize commercial content on the internet (McIlrath 2006; Wollslager 2010; Ali, Blades, Oates and Blumberg 2009), and effect studies with a micro-level approach focusing on specific types of online advertising (van Reijmersdal, Rozendaal and Buijzen 2012). Children's own accounts of how they experience, use and manage advertising while surfing on the internet have not received sufficient scholarly attention.

Andersen, Tufte, Rasmussen and Chan's (2008) survey-based study, touches upon the question of children's (age 10-13) attitudes towards internet advertising in Denmark and Hong Kong. However, this study is also an example of how television advertising is still at the center of attention; questions about online advertising are restricted to children's attitudes towards pop-up advertisements, while more questions are asked regarding television advertising, such as children's favorite commercials. Their findings concerning internet advertising show that the majority of children have negative attitudes towards pop-up advertisements (ibid. p. 197). Children's attitudes towards television advertising are more complex, "at the same time both appreciative and skeptical" (ibid. p. 198).

Concerning research with adolescents, Sandberg, Gidlöf and Holmberg (2011) interviewed Swedish fifteen-year-olds and observed how they visually interacted with online advertising. They found that teenagers hold negative attitudes towards advertising on the internet, which they perceived as irritating, and that they also reported different strategies they use to avoid advertisements - looking away, or holding their hands to cover areas with advertisements. The study by Sandberg et al. (2011) also shows that the adolescents avoided $90 \%$ of the adverts which were shown during a free surfing session.

\section{Aim and Research Questions}

Online advertising is a multidimensional phenomenon. A distinction can be made between advertising on advertiser-controlled sites, such as an "advergame" on a brand website, and advertising located on non-advertisers sites as a message within the context of other material, such as a banner advertisements (McMillan 2007: 20). This study concentrates foremost on online advertising which appears on non-advertiser sites, as these are forms of advertising which many children are familiar with (Småungar \& Medier 2010: 21). This type of advertising resembles advertising on television or in the press. It is often an add-on which follows with the use of a medium, and is mostly not the main reason why a person chose to engage with media (Grusell 2008: 24). When children surf the internet they, consequently, encounter advertising which intrudes with their preferred activities. Even though advertising generally is an add-on, it sometimes converts into the main content of the media use. Research has shown that children sometimes use television commercials as entertainment (Lawlor 2009). How children use advertising on the internet has not, to our knowledge, been studied previously. In light of this, the aim of the study was to analyze children's relationship with online advertising, with a focus on their views and practices. The following research questions guided the study:

RQ 1: What are children's views of online advertising? 
Carolina Martínez, Gunilla Jarlbro \& Helena Sandberg Children's Views and Practices Regarding...

RQ 2: How do children handle unwanted advertising on the internet?

RQ 3: How is advertising on the internet used by children?

\section{Theoretical Framework}

Michel de Certeau's theory of practices in everyday life (1984) has been utilized as a framework for contextualizing and interpreting the empirical data. In The Practice of Everyday Life (1984), de Certeau is concerned with what users, sometimes referred to as "consumers", do with cultural representations of society - "the products imposed by a dominant cultural order" (de Certeau 1984: xiii). People's different ways of using popular culture in their everyday lives are, according to de Certeau, "of a tactical nature" (ibid. p. 40). The concept of tactics is put in relation to the concept of strategy. A strategy is defined as:

The calculus of force-relationships which becomes possible when a subject of will and power [...] can be isolated from an "environment". A strategy assumes a place that can be circumscribed as proper (propre) and thus serve as the basis for generating relations with an exterior distinct from it. (ibid. p. xix)

Tactics are individual's everyday life practices in relation to the strategies. A tactic does not have a proper place, and is characterized by its temporal dimension:

It has at its disposal no base where it can capitalize on its advantages, prepare its expansions, and secure independence with respect to circumstances. The "proper" is a victory of space over time. On the contrary, because it does not have a place, a tactic depends on time - it is always on the watch for opportunities that must be seized 'on the wing'. (ibid. p. xix)

In de Certeau's theory power is based on having access to a proper place. Users are consequently positioned as the "dominated" (ibid. p. xi) and the "weak" (ibid. p. xix, 37, 40), and the tactics are understood as a form of resistance (ibid. p. xiv, 18). De Certeau stresses that the subordinated position of the users does not mean that they are passive (ibid. p. xi). Users are active and make "innumerable and infinitesimal transformations of and within the dominant cultural economy in order to adapt it to their own interests and their own rules" (ibid. p. xiv).

Applying the concepts of strategy and tactics to the specific subject of the present study, one can say that advertising on the internet is part of a (marketing) strategy, where marketers are the subjects of "will and power", and the advertisements on children's websites are the proper places. These advertisements are bases for "generating relations with an exterior", which in this case is children using the internet. In turn, tactics refer to what children do with online advertising while surfing on the internet. The power relationship between children and marketers is, in de Certeau's theory, in favor of the marketers, as they have access to a proper place. However, as stressed above, children are active, and the present study has its focus on children's accounts of how they actively engage with advertising while surfing on the internet.

Michel de Certeau's The Practice of Everyday Life has influenced research areas such as active audience studies, geography and urban studies (Crang 2000: 136; Crang 2010; Goldstein and Machor 2008: 50). De Certeau's work has also incurred critique for 
being uncritical, and for accepting and presuming a status quo where users with their tactics are comfortable not having a proper place (Morris 1990: 31). This critique must be taken seriously as there is a tendency in de Certeau's work (1984) to portray tactics in an overly positive manner; users are consequently said to be enjoying their tactics (ibid. p. xxii, xxiv, 18). De Certeau can be criticized for not problematizing the experiences of tactics sufficiently, just assuming that they are enjoyable acts of resistance.

\section{Method}

\section{Study Design and Sampling Procedure}

The interview study was part of a larger study which also aimed at investigating children's visual interaction with advertising on the internet, using eye-tracking equipment. The study was conducted at a primary school with children from mixed socioeconomic and cultural backgrounds, in a small town in the south of Sweden. Children in two thirdgrade classes were informed about the study and asked if they wanted to participate. An informed consent form and a questionnaire on the children's basic internet habits were distributed amongst the children to be filled in at home and returned. In total, 20 children, ten girls and ten boys, took part in the interview study. Of these, 18 were nineyear-olds, and two had reached the age of ten.

The study took place at the end of November and the beginning of December 2011. The individual interviews were conducted in a small room next to the classroom. Before the interviews the boys and girls performed some tasks related to the eye-tracking study. After a short session of free surfing, the children's abilities to distinguish advertising from other content were tested. It was considered relevant to gain an insight into their basic knowledge of online advertising, since research on internet advertising literacy indicates that children are less skilled at identifying advertising on web pages than on television (Ali et al. 2009). The test also functioned as an introduction to the topic for the following interviews. The children were asked to identify banner advertisements on two screenshots from two popular online gaming sites. The results of the test showed that most children managed to identify the banner advertisements. ${ }^{1}$ Having the test before the interviews might be criticized for having a priming effect on the children. The interview data show, however, that during the interviews they also related to other forms of internet advertising than banner advertisements, and that they mostly referred to previous experiences from their everyday lives.

The final step in the research design was feeding back the results to the children. They confirmed the findings by expressing new thoughts and experiences, which were in line with the interview results.

\section{Interview Procedure and Data Analysis}

The qualitative interview was considered a suitable method for the purpose of the study, as it elicits information about events and processes of everyday life that are difficult to observe with other methods (Lindlof and Taylor 2011: 173). The individual interview was elected as it brings forth information on how each individual relates to the topic of the study, and as it gives room to all interviewees to give their view on the subject (Freeman and Mathison 2009: 101). The interviews were semi-structured with mainly open-ended 
questions. The aim was to stimulate the children to talk about their relationship with online advertising. The children were asked to think about when they surf at home, and describe advertisements that they had paid attention to. They were asked if they look at advertising while surfing on the internet, and to describe what online advertising can look like. To concretize the question "What is your view of online advertising?", it was formulated as a directive compare-contrast question (Lindlof and Taylor 2011: 207): "What do you think about online advertising - can it for instance be annoying or entertaining?" Concerning possible uses of advertising, we asked questions that referred to three categories: advertising as entertainment, as social interaction and as information, which are categories that have been identified in previous research with adults (O'Donohoe 1994).

In order to enhance the validity of the self-reported data, we wanted to make sure that the children were actually talking about online advertising. When the boys and girls gave examples of specific advertisements, they were therefore asked where they had seen the specific advertisement. They often gave evidence which confirmed that they were actually talking about advertising on the internet. Clues that indicated this were statements such as "but I didn't click on it", or the "It was on Spela" (a Swedish gaming site). The interviews with the children showed, with some exceptions, that they were able to give a good account of their experiences of online advertising. In contrast to this, three children talked about website content which did not seem to refer to advertising. These parts of the interviews have been excluded from the analysis presented here.

The interviews were audio recorded and lasted between 10 and 25 minutes, with an average of 15 minutes. There was, thus, considerable variation concerning the children's willingness and possibilities to talk about the interview subject. Some of the boys and girls answered briefly and did not develop their thoughts, something which may be due to lack of interest regarding the interview subject. That children can be bored by the topic have been observed in other interview studies with children (Pynt Andersen 2007: 226). The short answers can also depend on shyness, or discomfort in the interview situation.

The interviews were transcribed and then analyzed using thematic coding as described by Flick (2006: 307-312). This coding procedure is designed for research issues concerning "the social distribution of perspectives on a phenomenon or process" (ibid p. 307). In the first step, each interview is treated as a single case where narratives and statements are coded in categories (ibid. p. 312). In the second step, the categories of the single cases are compared in order to see similarities and differences (ibid. p. 310).

\section{Participant Characteristics}

The amount of time spent with different media can vary widely within the same age group (Findahl 2012b). This was also evident in the present study; according to the questionnaire there were important individual differences concerning time spent on the internet amongst the children. ${ }^{2}$ Some of them used the internet for less than an hour a week, and some used the internet 10-12 hours a week. The average time spent on the internet during a week was 5 hours. Converting this number to a day unit of 43 minutes makes it comparable to national survey data on 9-12-year-olds' internet habits. According to the Swedish survey data, $49 \%$ of the 9-12-year-olds spend less than an hour a day on the internet, and 32\% spend between 1 and 2 hours (Ungar \& Medier 2010: 36). The children, thus, had similar internet habits to nine-year-olds in general. 
The questionnaire also revealed that the preferred activity on the internet among both girls and boys was playing online games. This was followed by listening to music and looking at video clips. This is also consistent with national survey data (Ungar \& Medier 2010: 47). The most frequently listed website category was online-game sites, and the unique site most frequently used was YouTube. The children listed 35 unique websites and the majority of these contain advertising (28/35). Websites with a micropayment model were few (4/35), together with non-commercial websites (3/35). This shows that the children's activities on the internet take place in a highly commercialized environment.

\section{Results}

\section{Children's Views of Online Advertising}

Most children said, at the beginning of the interviews, that they do not pay attention to advertising on the internet. Exceptions were a girl and a boy, each of whom "sometimes looks" (Girl 002, Boy 004), and another child who mentioned that he "usually looks" (Boy 010). This reflects that the children generally view advertising as a form of media content which has little relevance to them. However, after this initial rejection of their engagement with advertising on the internet, they went on describing specific advertisements they had seen, and situations where they usually encounter advertising while surfing. When they reflected in more depth on their relationship with online advertising, the children showed basically two ways of relating to the subject: children who had a straightforward negative view, and children who were more ambivalent. The interviewees were evenly distributed amongst the two groups.

Children belonging to the first group thought that online advertising is solely irritating. They were greatly annoyed by advertisements before online games, moving advertisements, and the fact that advertising is present on most websites. They gave no examples of entertaining advertisements, and said that they had not talked with their friends about advertising. Children belonging to this group were generally shorter in their answers than children in the other group. It may be the case that these children have adopted a critical perspective on advertising found amongst parents (Smaiungar \& Medier 2010: 40), or that they found it more difficult to talk about the subject for different reasons (see above).

Children with an ambivalent view said that advertising on the internet can be both irritating and entertaining. They claimed that they pay attention to advertisements which are considered funny, interesting or relevant to them. Examples they gave were: advertisements for games, clothes, new movies, and advertisements with funny and cute characters. The advertisements that are shown before online games were perceived as irritating and boring. An illustrative example of how children with this ambivalent viewpoint expressed themselves is articulated below:

Sometimes they [advertisements] can be annoying and sometimes they can be funny (Girl 114).

This view of online advertising is in line with O'Donohoe's (2001) claim that ambivalence is characteristic of attitudes towards advertising. Complex attitudes towards advertising have also been found in research on television advertising (Andersen et al. 2008: 198). 


\section{Children Dealing with Unwanted Advertising}

The children's negative experiences of online advertising mostly referred to advertisements shown before online games, as was described above. In this particular situation, the advertisement appears in the same place as the preferred content. This puts audiences in a "forced exposure mode", an experience often resulting in frustration and avoidance (Li and Leckenby 2007: 213; Hood and Schumann 2007: 195). Pre-rolls, or interstitials, as this form of advertising can also be called (Li and Leckenby 2007: 213), can be seen as a strategy used by advertisers to draw attention to the ads. A certain amount of time has to pass before the user can continue his/her activity, and the boys and girls said that they use different tactics in order to avoid the advertisements. The children's descriptions of how they are annoyed by these pre-rolls, and the tactics they use to avoid them, resemble how children relate to advertising on television (Pynt Andersen 2007: 226).

One tactic, which was reported by several of the interviewees, was to focus on the line below the advertisement where you can see how much time is left before the game can be started. This was generally described as a boring activity. One boy said:

When I play on Spela.se, then it loads, and I mostly look down, where it loads. Because later appears 'the game has loaded, click to play the game'. And I mostly wait for that to appear [...] and then, I don't look at what's above, the advertisement. (118)

Another avoidance tactic reported by the children was to go away for a moment when the ad loads:

Boy: When I enter a game called Happy Wheels [difficult to hear], when I enter that there is a really long advertisement. (007)

$C M$ : A long advertisement. Does it appear before the game?

Boy: When I start there is a line loading really slowly and there is an advertisement as long as it loads.

CM: What do you do then? Do you look at it?

Boy: Sometimes I go to Michael [his big brother] and check out what he's doing $[\ldots]$ and then I go back when it has loaded.

Online advertising, thus, seems to have the same function as television advertising structuring time (O'Donohoe 1994), and gives a small break which can be used for different purposes. Another interviewee said that advertisements before online games were tiresome, but he could also use the break to go and see his dog or watch television: "Either I go down to my dog or I watch TV in the meantime (010)." The boy told us that he often sits in front of the television when he surfs the internet. Thus, multi-tasking is another avoidance tactic reported by the children: "Because I mostly sit upstairs by the TV when I'm online. So, if there is advertising I can just sit there and watch [television] meanwhile (010)." Using multiple media at the same time is common among children and young people today (Rydin and Sjöberg 2010: 93, Tufte 2011: 37). This example indicates that the presence of and access to different forms of media platforms gives the individual an increased opportunity to select the preferred media content, and, consequently, to avoid advertising. 
Avoidance tactics were also described in relation to YouTube. One boy told us about an advertisement that he had seen often on the site:

When I enter YouTube, they appear. If I want to look at something here, then an advertisement pops up and there is a heart, and it says that there is ' 4031 single people online to chat with' and everything. (100)

When asked about his opinion on these ads he said that it was boring and tiresome when they appeared, and explained why:

Boy: Because then you have to take the mouse and click. You have to 'X-it' [X:a] and get rid of it.

CM: Does it bother you? Does it appear in front of what you want to see?

Boy: Yes, because it appears before the film, and there is a yellow spot there, a line, and then when the red comes on the white, it just comes up on the screen.

$C M$ : What do you think about that?

Boy: A little boring because I can't stand it. [...] I'm too tired to do it.

The boy was so familiar with the loading line that he even remembered the colors. The construction of a new word, "X-it" (to click the little square with a cross at the top corner of the advertisement) shows that this situation has become a part of his everyday life. He expressed a kind of "wearout", a mode of frustration in relation to advertising that is repeatedly shown (Hood and Schumann 2007: 195).

The children also reported on situations where they had difficulties avoiding advertisements. In these cases they had involuntarily engaged with advertising. The examples of online advertising mentioned during the interviews give reason to believe that perceptual prominence (Buijzen et al. 2010: 439), in the sense of frequent appearance, made it difficult for them to avoid the advertisements. The multitasking boy, when asked if he could give an account of a specific advertisement that he had seen, remembered an advertisement which had no personal relevance (ibid. p. 439) for him, but that had been exposed over and over again on the website:

Boy: No, it is mostly that one with the USB memory stick. It is mostly that one so I know it by heart. (010)

CM: You have looked at it a lot. Is it because it has appeared a lot?

Boy: Yes, it is mostly that ad that appears, there are a lot of them.

$C M$ : Is it a picture?

Boy: No, there are two guys talking on mobile phones and in the end a USB appears.

$C M$ : What do you think about the frequent appearance?

Boy: Well it becomes boring when you have seen it a couple of times.

The boy talking about the advertisement for single people online on YouTube said that he had also paid attention to it repeatedly: 
I watch YouTube and every time I enter I see the one with single people. [...] I don't know why it appears all the time, and on many sites it just comes up '500 single people online', and I think, God, how embarrassing. (100)

These examples indicate that advertisements which are shown repeatedly are difficult to avoid. Why tactics of avoidance have not been used in these cases can also be explained by the fragility of avoidance tactics, as a tactic has "no base where it can capitalize on its advantages, prepare its expansions, and secure independence with respect to circumstances" (de Certeau 1984: xix). A tactic requires constantly new efforts, as it "operates in isolated actions, blow by blow [...] What it wins it cannot keep" (ibid 1984: 37). In view of this, avoidance tactics fail easily, and the children resign to circumstances, tired of the constant need to repeat their tactics.

Other types of advertisements which, according to the interviewees, are difficult to handle are those that have to do with color and motion. One boy said that advertisements with bright colors annoy him. Another girl felt that moving advertisements are annoying:

Sometimes there are images which move around, and that is annoying when you want to do other things. Then the advertisement is there on the side, and it becomes so annoying. (003)

The participant described a situation where advertisements containing motion intrude on her preferred activity. It seems as if moving advertisements made it difficult for her to filter information the way she wanted to, as the moving advertisement attracted her attention involuntarily.

\section{Children's Uses of Online Advertising}

As indicated above, children with an ambivalent view of online advertising were those who also reported on different ways in which they use advertising on the internet. In the interview data there are examples of uses of advertising as entertainment, information and social interaction. It was the category of entertainment, though, which generated the most detailed descriptions, and therefore will be in focus here. Online advertising as entertainment revolved around animated cute and funny figures. The children brought up examples of advertisements with animals, such as a chicken, a bear, and a sheep. Some children remembered specific brands in connection with these examples, while others exclusively remembered the figures. Some of these figures are spokes-characters, "nonhuman characters used to promote a product or a brand" (Garretson and Niedrich 2004: 25), a common marketing technique which often creates high levels of attention, liking and character recall (Neeley and Schumann 2004: 18). These examples of advertising can be categorized as rich media advertisements, based on the descriptions given by the children. Rich media advertising consists of moving images, sound and interactive features (Li and Leckenby 2007: 214), and provide a "brand-as-experience", a form of advertising that is perceived to be sticky and maintains viewers' attention more easily than other types of advertising (Coyle and Gould 2007: 84-85). Designing advertisements with cute and funny figures is a strategy used by marketers to attract children's attention (Buijzen et al. 2010: 431; Neeley 2007: 344). One girl who found advertisements with cute figures entertaining mentioned an advertisement with a chicken, and remembered two brands in connection with that advertisement: 
Girl: Yeah, one with a Telia-chicken [Telia is a company that provides telephone services]. It was a yellow chicken at Easter. You could get free internet until Easter. (114)

CM: It's a long time ago, and you remember it? Was it on the internet?

Girl: Yes. [...] It jumped around on an Iphone. [...] I looked at it for a while but I didn't enter it - I didn't click on it, but I looked at it.

Another girl also brought up an advertisement with an entertaining animal in connection with an advertisement for mobile phones. When she is bored with the content on the website, advertising becomes a source of entertainment:

Girl: There can be a sheep and mobile phones, and it can tell stories. (009)

$C M$ : Was it the sheep that could tell stories?

Girl: Yes, and then he says 'do you want a new mobile phone?' [...]

$C M$ : When can it [online advertising] be entertaining?

Girl: If there is something funny, when you are bored.

$C M$ : Do you have an example of something that can be funny?

Girl: When the sheep said that.

Interactivity is a special feature of online advertising (McMillan 2007: 17). During the interviews, the boys and girls gave examples of how they had interacted with funny advertisements:

Girl: It was an advertisement that came up on a web page and they advertised a mobile, and the bear was next to it, and you could click on the bear and music started to play, and it said something. (102)

$C M$ : Do you remember what it said?

Girl: Welcome.

$C M$ : Did you click on it?

Girl: The first time I clicked on it was because I wanted to see, and I clicked and it said 'Welcome.' [...]

CM: Why did you want to do that?

Girl: It said 'Click on me; I'm going to say something.'

In the last part of the quotation, the girl gives an account of how she clicked on the advertisement because the bear told her to, indicating that this form of marketing technique, which obviously takes advantage of children, can be successful.

Another participant related how he had interacted with an advertisement for unhealthy food. When asked if online advertising can be entertaining, the boy brought up an advertisement for donuts: 
Carolina Martínez, Gunilla Jarlbro \& Helena Sandberg Children's Views and Practices Regarding...

Boy: You should buy donuts in a store. And there was an elf on an image, and if you took the mouse and clicked on it, then he lifted his arms and ate a donut. And then he ate it in different ways. (011)

$C M$ : Do you remember the brand?

Boy: It only said 'buy good donuts' or something like that underneath and there was an elf eating.

As we can see in these examples of entertaining advertisements, children mainly brought up advertisements for mobile phones. Mobile phones play an important role in young people's everyday lives (Stald 2008: 147). Marketers aim at constructing brand loyalty in early ages, and to foster certain behaviors and identities that require commercial commodities (Herring 2008: 73). Designing advertisements for mobile phones which appeal to children can be seen as a marketing strategy with the intention to attract children to the world of mobile phones.

Children's uses of advertising as entertainment, with a focus on cute and funny figures, and not on the product advertised, can be interpreted as tactics, as they are examples of how users make "innumerable and infinitesimal transformations of and within the dominant cultural economy in order to adapt it to their own interests and their own rules" (de Certeau 1984: xiv). However, as cute and funny figures are used to attract children's attention to specific advertisements, the objectives of marketers are fulfilled by the tactics used by children.

Social interaction in relation to online advertising is connected to the use of advertising as entertainment. One boy described how he and a friend had laughed when they had seen a funny advertisement on the internet:

Boy: Sometimes there are funny advertisements on the computer, and then we usually laugh. (004)

$C M$ : Do you remember a specific advertisement and where it appeared?

Boy: It was on Silvergames, where there was a funny tomato ketchup advertisement.

CM: Can you describe it?

Boy: It was funny music. [...] A guy in an office that had lots of tomatoes.

$C M$ : Do you remember the brand?

Boy: Felix ketchup, I think.

Even though the main attraction of the advertisement was the funny content, the boy had also noted the brand, an illustrative example of "brand-as-experience". Other examples of social interaction in connection with online advertising were related to situations where the children had experienced intrusive advertisements. When asked whether he had talked about advertising with his friends, one boy said: "We only talked about how irritating it is when it pops up (008)." Commenting on their feelings with their friends may also be interpreted as a way for children to cope with unwanted advertising on the internet. 
The interview data also showed that some children use advertising on the internet as information on products in which they are interested. The personal relevance of advertising, as age-appropriate product categories is considered a factor that can augment the amount of attention paid to a message (Buijzen et al. 2010: 439). Some children related that they had seen advertisements for computer- and television-games, toys and clothes, and that they had asked their parents to buy the products. Some of them had only expressed their desires, while others had been able to buy the product. Concerning the use of advertising as information, the children did not give any detailed examples of specific advertisements they had seen. It was the products which they had bought, or wanted to buy, that they remembered and brought up during the interviews.

\section{Summary and Conclusion}

This article has approached the question of children's relationship with online advertising using qualitative interviews. Individual interviews were considered a relevant method as they can elicit information on everyday life practices, which are difficult to study with other methods. However, this choice also constitutes a limitation of the study. Other methods, such as group interviews and observations, could have elicited other data, and future research should preferably employ such methods in order to gain a deeper insight into children's relationship with the commercial media environment on the internet.

Regarding children's views of online advertising, the results show that the children were ambivalent or negative towards advertising on the internet. Previous research on children's views of advertising on the internet has shown that young children are mostly (Andersen et al. 2008), and teenagers are exclusively (Sandberg et al. 2011) negative towards advertising on the internet. The present study shows a somewhat different picture, where advertising on the internet also sometimes constitutes a source of entertainment and information for at least half of the children who participated in the study. Ambivalent and complex attitudes are also shown in research on television advertising (Andersen et al. 2008; O'Donohoe 2001).

The study also indicates that children, like teenagers (Sandberg et al. 2011), have developed different avoidance tactics to cope with unwanted advertising on the internet. Tactics described by the interviewees were to focus on the "loading" line below advertisements shown before online games, to leave the computer to see other family members, and to use multiple media simultaneously. In contrast to this, the children also expressed how they sometimes have difficulties coping with and avoiding advertising on the internet. They are annoyed by advertisements which appear frequently, and advertisements with bright colors and motion.

The boys and girls reported on several ways in which they make use of online advertising, as entertainment, information and social interaction, where advertising as entertainment was described most in detail. The children reported frequently on advertisements with animated cute and funny figures, predominantly animals. Specific brands were also described in relation to some of the advertisements that were brought up during the interviews, yet the main focus was on the cute and funny characters. Children's uses of television advertising as entertainment are well documented in previous research (Lawlor 2009). The present study shows how advertising on the internet is also used as entertainment by children. 
Michel de Certeau's theory of practices in everyday life (1984) was used as a framework for theorizing children's relationship with online advertising. Some of the interview results reveal new dimensions regarding the concept of tactic. As mentioned in the theory section, de Certeau depicts tactics as enjoyable acts of resistance. This study has shown that children generally perceive avoidance tactics as boring activities, which nevertheless are preferred to watching advertisements. This shows that there is a need to focus not only on the tactics, but also the experiences of tactics, as this further sheds light on the imbalance of power existing between children and marketers on the internet.

In de Certeau's theory, the concepts of strategy and tactics are depicted as more or less separate entities. However, children's uses of online advertising as entertainment actually fulfill the aim of the strategies, something which problematizes the view of tactics as independent acts of resistance. Marketers' strategies to capture children's attention are regulated in the Swedish law which dictates that advertisements in television broadcasts "may not aim at capturing the attention of children below the age of twelve" (Radio- och tv-lag 2010: 696). In light of the results of the present study, policy makers might want to consider possibilities for implementing the same regulation on websites aimed at children. In doing so, the power relationship between marketers and children can be balanced in favor of the children.

\section{Notes}

1. The first screenshot contained two banner advertisements; one advertising a skin product, and another advertising the movie Happy Feet 2. The second screenshot contained one banner advertisement for the company Onlinepizza.se. On the first screenshot 19/20 children identified the Happy Feet advertisement. The skin product ad was identified by $17 / 20$ children. On the second screenshot all children identified the pizza advertisement.

2. Two outliers, concerning time spent on the internet, have been excluded from the analysis, as they would have distorted the overall picture. These answers, 30 and 42 hours respectively, may be due to a misinterpretation of the question.

\section{References}

Ali, M., Blades, M., Oates, C. \& Blumberg, F. (2009) 'Young Children's Ability to Recognize Advertisements in Web Page Designs', The British Journal of Developmental Psychology, 27(Pt 1): 71-83.

Andersen, L.P., Tufte, B., Rasmussen, J. \& Chan, K. (2008) 'The Tweens Market and Responses to Advertising in Denmark and Hong Kong', Young Consumers, 9(3): 189-200.

Buckingham, D. \& Tingstad, V. (2010) 'Introduction', in D. Buckingham \& V. Tingstad (eds.) Childhood and Consumer Culture, pp. 1-14. Basingstoke: Palgrave Macmillan.

Buijzen, M., Van Reijmersdal, E.A. \& Owen, L.H. (2010) 'Introducing the PCMC Model: An Investigative Framework for Young People's Processing of Commercialized Media Content', Communication Theory, 20(4), 427-450.

\section{Acknowledgements}

This research was supported by the Swedish Research Council (grant id 421-2010-1982), and the Crafoord Foundation (grant id 20100899). There are no commercial interests or relationships involved in this research.

The authors also want to thank Joanna Doona, Annette Hill, Nils Holmberg and Tobias Olsson at the Department of Communication and Media, Lund University, for their valuable feedback on the text. 
Coyle, J. \& Gould, S. (2007) 'Internet Integrated Marketing Communications (I-IMC) Theory and Practice', in Schumann, D. \& Thorson, E. (eds.) Internet Advertising: Theory and Research, 69-88. New York: Taylor \& Francis Group.

Crang, M. (2000) 'Relics, Places and Unwritten Geographies in the Work of Michel de Certeau (1925-1986)', in Crang, M. \& Thrift, N. (eds.) Thinking Space (Vol. 9), pp. 136-153. London: Routledge.

Crang, M. (2010) 'De Certeau, Michel', in Hutchison, R. (ed.) Encyclopedia of Urban Studies, pp. 209-211. Thousand Oaks: Sage Publications.

de Certeau, M. d. (1984) The Practice of Everyday Life. Berkeley: University of California Press.

Ekström, L. \& Sandberg, H. (2010) Reklam funkar inte på mig: Unga, marknadsföring och internet (Vol. 2010:502), [Advertising has no effect on me: Youth, marketing and the internet]. Köpenhamn: Nordiska Ministerrådet.

Findahl, O. (2012a) Svenskarna och Internet 2012, [The Swedish people and the internet]. Stockholm: .SE - Stiftelsen för Internetinfrastruktur.

Findahl, O. (2012b) 'Barn och ungas medieanvändning i Internet-världen', [Children and young people's media use in the Internet-world], in Carlsson, U. (ed.) Barn och ungas medieanvändning i nätverkssamhället [Children and young people's media use in the network society], pp. 9-92. Göteborg: Nordicom.

Flick, U. (2006) An Introduction to Qualitative Research. London: Sage.

Freeman, M. \& Mathison, S. (2009) Researching Children's Experiences. New York: Guilford Press.

Garretson, J.A. \& Niedrich, R.W. (2004) 'Spokes-Characters: Creating Character Trust and Positive Brand Attitudes'. Journal of Advertising, 33(2), 25-36.

Goldstein, P. \& Machor, J.L. (2008) New Directions in American Reception Study. Oxford: Oxford University Press.

Grusell, M. (2008) Reklam - en objuden gäst? Allmänhetens uppfattningar om reklam i morgonpress och $t v$ [Advertising - an uninvited guest? The public's views of advertising in the press and television]. Göteborg: Göteborgs universitet (JMG).

Herring, S. (2008) 'Questioning the Generational Divide: Technological Exoticism and Adult Constructions of Online Youth Identity', in Buckingham, D. (ed.) Youth, Identity, and Digital Media, pp. 71-92. Cambridge: MIT Press.

Hood, K. \& Schumann, D. (2007) 'The Process and Consequences of Cognitive Filtering of Internet Content', in Schumann, D. \& Thorson, E. (eds.) Internet Advertising: Theory and Research, pp. 185-202. New York: Taylor \& Francis Group.

Lawlor, M-A. (2009) 'Advertising Connoisseurs: Children's Active Engagement with and Enjoyment of Television Advertising'. Irish Marketing Review, 20(1), 23-34.

Li, H. \& Leckenby, J. (2007) "Examining the Effectiveness of Internet Advertising Formats", in Schumann, D. \& Thorson, E. (eds.) Internet Advertising: Theory and Research, pp. 203-224. New York: Taylor \& Francis Group.

Lindlof, T.R. \& Taylor, B.C. (2011) Qualitative communication research methods. Thousand Oaks, Calif: Sage.

'Marknadskommunikation 2011' [Market communication 2011], IRM. URL (consulted 15 August 2012) http:// www.irm-media.se/tabell_reklamstatistik2005.aspx

McIlrath, M. (2006) Children's Cognitive Processing of Internet Advertising. University of California, Santa Barbara: Dissertations Publishing.

McMillan, S.J. (2007) 'Internet Advertising: One Face or Many?', in Schumann, D. \& Thorson, E. (eds.) Internet Advertising: Theory and Research, pp. 1535. New York: Taylor \& Francis Group.

Morris, M. (1990) 'Banality in Cultural Studies', in Mellencamp, P. (ed) Logics of Television: Essays in Cultural Criticism, pp. 14-43. Bloomington: Indiana University Press.

Neeley, S.M. \& Schumann, D.W. (2004) 'Using Animated Spokes-Characters in Advertising to Young Children: Does Increasing Attention to Advertising Necessarily Lead to Product Preference?', Journal of Advertising, 33(3), 7-23.

Neeley, S.M. (2007) 'Internet Advertising and Children', in Schumann, D. \& Thorson, E. (eds.), Internet Advertising: Theory and Research, 343-362. New York: Taylor \& Francis Group.

O'Donohoe, S. (1994) 'Advertising Uses and Gratifications'. European Journal of Marketing, 28(8/9), 52-75.

O’Donohoe, S. (2001) 'Living with Ambivalence: Attitudes to Advertising in Postmodern Times'. Marketing Theory, 1(1), 91-108.

Pynt Andersen, L. (2007) 'Why Don't They just Show the Product?', in Ekström, K.M. \& Tufte, B. (eds.) Children, Media and Consumption. On the Front Edge, pp. 221-234. Göteborg: Nordicom.

Radio- och tv-lag 2010: 696, kapitel 8, paragraf 7. [The Swedish broadcast law 2010: 696, chapter 8, paragraph 7]. URL (consulted 2013-01-29): https://lagen.nu/2010:696\#K8P3S2

Rydin, I. \& Sjöberg, U. (2010) 'From TV Viewing to Participatory Cultures' in Carlsson, U. (ed.) Children and Youth in the Digital Media Culture: From a Nordic Horizon, pp. 87-101. Nordicom: University of Gothenburg. 
Carolina Martínez, Gunilla Jarlbro \& Helena Sandberg Children’s Views and Practices Regarding...

Sandberg, H. (2011) 'Tiger Talk and Candy King: Marketing of Unhealthy Food and Beverages to Swedish Children'. Communications - European Journal of Communication Research, 36(2), 217-244.

Sandberg, H., Gidlöf, K. \& Holmberg, N. (2011) 'Children's Exposure to and Perceptions of Online Advertising', International Journal of Communication 5: 21-50.

Småungar \& Medier 2010: Fakta om små barns användning och upplevelser av medier (2010) [Young Children \& Media 2010: Facts about young children's uses and experiences of media]. Stockholm: Kulturdepartementet.

Stald, G. (2008) 'Mobile Identity: Youth, Identity, and Mobile Communication Media', in Buckingham, D. (ed.) Youth, Identity, and Digital Media, 143-164. Cambridge: MIT Press.

Tufte, B. 'Tweens as Consumers - with Focus on Girls' and Boys' Internet Use', in Ekström, K.M. and Tufte, B. (eds.) Children, Media and Consumption. On the Front Edge, pp. 93-106. Göteborg: Nordicom.

Tufte, B. (2011) 'Tweens og medier' [Tweens and media], in Andersen Pynt, L. (ed.) Tweens - mellem medier og markevarer [Tweens - between media and brands], pp. 29-51. Gylling: Samfundslitteratur.

Ungar \& Medier 2010: Fakta om barns och ungas användning och upplevelser av medier (2010) [Kids \& Media 2010: Facts about how children and youth use and experience media]. Stockholm: Kulturdepartementet.

van Reijmersdal, E.A., Rozendaal, E. \& Buijzen, M. (2012) 'Effects of Prominence, Involvement, and Persuasion Knowledge on Children's Cognitive and Affective Responses to Advergames'. Journal of Interactive Marketing, 26(1), 33-42.

Wasko, J. (2010) 'Children's Virtual Worlds: The Latest Commercialization of Children's Culture', in Buckingham, D. \& Tingstad, V. (eds.) Childhood and Consumer Culture, pp. 113-129. Basingstoke: Palgrave Macmillan.

Wollslager, M.E. (2010) Media Literacy Training's Effects on Recall: Children's Awareness of Online Advertising on Neopets. Regent University: UMI Dissertations Publishing.

CAROLINA MARTÍNEZ, Ph.D. Student, Department of Communication and Media, Lund University, carolina.martinez@kom.lu.se

GUNILLA JARLBRO, Ph.D., Professor, Department of Communication and Media, Lund University, gunilla.jarlbro@kom.lu.se

HELENA SANDBERG, Ph.D., Associate Professor, Department of Communication and Media, Lund University, helena.sandberg@kom.lu.se 
